\title{
Genetic Similarity Shared by Best Friends Among Adolescents
}

\author{
Guang Guo \\ Carolina Population Center and Department of Sociology, University of North Carolina at Chapel Hill, Chapel Hill, North Carolina, \\ United States of America
}

T. wo observations suggest a genetic similarity among close friends: (1) the observed similarity among friends in certain traits and behaviors; (2) the evidence that many of these traits and behaviors have a genetic component. This hypothesis is tested using monozygotic (MZ) twins, dizygotic (DZ) twins, full biological siblings, and their best friends from the National Longitudinal Study of Adolescent Health (Add Health). Whether the resemblance between $M Z$ twins' friends is larger than that between friends of DZ twins and full siblings is investigated with respect to 4 individual traits or behaviors: grade point average (GPA), AHPVT (the version Peabody Picture Vocabulary Test [PPVT] designed for Add Health), aggressive behavior, and depression. Our hypothesis is supported in analyses among same-sex friends (not among different-sex friends) for GPA, aggressive behavior, and AHPVT.

\section{Hypothesis}

Empirically, two sets of well-established findings suggest the hypothesis of a genetic similarity among close friends, at least with respect to certain attitudes, traits, and behaviors: (1) friends share certain attitudes, traits and behaviors (e.g., Bearman \& Bruckner, 2000; Berelson et al., 1954; Duncan et al., 1972; Matsueda, 1982; Matsueda \& Heimer, 1987); (2) many of these attitudes, traits, and behaviors have been shown to be partially genetic (e.g., Plomin et al., 2003; Plomin et al., 2001; Rodgers et al., 1999). These findings point to the possibility of a genetic similarity among best friends because they are similar in certain characteristics and because the source of the similarity is partially genetic.

A hypothesis of genetic similarity shared by spouses and friends (Rushton, 1989) was suggested to expand Hamilton's (1964) theory of inclusive fitness. Hamilton's theory was put forward as an explanation for altruism: individuals who perform altruistic acts towards genetic relatives are more efficient in spreading their genes (inclusive fitness) than individuals who only attempt to spread their genes through their own offspring (individual fitness). A number of studies have tested the hypothesis of genetic similarity by showing that spouses and close friends are more similar than randomly paired individuals and that the friends and spouses of more genetically related individuals (e.g., monozygotic [MZ] twins) are more similar to each other than are those of less genetically related individuals (e.g., dizygotic [DZ] twins; Baker \& Daniels, 1990; Daniels \& Plomin, 1985; Iervolino et al., 2002; Manke et al., 1995; Rowe \& Osgood, 1984; Rushton \& Bons, 2005).

In this analysis, we test the hypothesis of genetic similarity shared by best friends among adolescents using $\mathrm{MZ}$ twins, $\mathrm{DZ}$ twins, and full siblings as well as their best friends collected by the National Longitudinal Study of Adolescent Health (Add Health; Harris et al., 2003). Our analysis makes at least three contributions. First, we use data on both genetically related individuals and their friends directly. In almost all previous empirical tests, friends data are reported by genetic relatives. The perceptions of others' behavior have been considered unreliable because the reporters tend to project their own behavior onto others (Bauman \& Ennett, 1996). In Add Health, both the siblings and their friends are participants of the study. Second, we perform statistical tests to find out whether the friends of MZ twins are significantly more similar to each other than are those of DZ twins. No previous study appears to have performed such a test. Third, we provide a detailed description and examination of the biometrical research design for the hypothesis testing.

\section{Similarity Among Friends}

It has long been recognized that friends or peers tend to hold similar attitudes, exhibit similar attributes, or engage in similar behaviors. Berelson et al. (1954) found that individuals with best friends who are Democrats are more likely to vote for Democratic presidential candidates than individuals with Republican friends. Duncan et al. (1972) reported that students whose friends have college plans are more likely to have college plans themselves controlling for

Received 9 May, 2005; accepted 1 June, 2005.

Address for correspondence: Guang Guo, CB\#3210, University of North Carolina, Chapel Hill, NC 27599-3210, USA. E-mail: guang_guo@unc.edu 
social class. Friends are found to be similar in height (Berkowitz, 1969), activities, needs, attitudes, and personality (Berscheid \& Walster, 1978). The incidence of delinquent behavior was found to be associated with the delinquency of the peer group (Matsueda 1982; Matsueda \& Heimer, 1987). Girls who had low-risk friends in their immediate circle of friends or in their peer groups were much less likely to experience sexual intercourse or pregnancy than girls who had averageor high-risk friends (Bearman \& Bruckner, 2000). Lazarsfeld and Merton (1954) introduced the term 'homophily' to describe the similarity in attitudes, attributes, and behaviors among close friends.

\section{Friends Effects Versus Selection Effects}

Scholars have offered two interpretations for the observed similarity between friends. The traditional view tends to view influences from peers and friends as causal. That is, friendship changes the behaviors of the individuals in the friendship and makes them more similar to each other. Adolescent behavior is considered especially vulnerable to the influences of friends and peers. One well-publicized view (Harris, 1995) argued recently that socialization mainly takes place in the peer groups of childhood and adolescence and, in comparison, parents do not have any important longterm effects on child development.

Earlier psychological literature often considered social or peer pressure the primary process of influence between friends. Bronfenbrenner (1967, 1970) argued that peers can change children's behavior because they put pressure on them. Later work has demonstrated a whole spectrum of influence mechanisms from coercive pressure at one extreme to something very close to a reasoned debate at the other extreme (Bandura, 1977; Berndt, 1999; Dishion et al., 1999; Dishion et al., 2001; Hartup, 1983; Piaget, 1932/1965).

Most researchers acknowledge that not all the similarity among friends is due to friend influence (second interpretation). Two individuals may become friends because they are similar in some characteristics to each other (see review by Berndt et al., 2002; Kandel, 1978). Scarr and McCartney (1983) argued that children are not only influenced by environment, they also actively participate in the creation of their own environment. Children tend to seek the right environment that matches their own genetic propensities. Friends and peers are a natural part of an adolescent's environment.

Part of the similarity between friends may thus be due to selection rather than influence. Researchers generally use the term 'selection' to describe all processes, conscious or not, in which individuals similar in certain characteristics become friends (Berndt et al., 2002). Sociological (Bearman \& Bruckner, 2000; Kandel, 1978) and epidemiological (Bauman \& Ennett, 1996) literature also refer to this as an issue of friends versus selection effects. Economists sometimes treat this as the problem of endogenous group membership (Moffitt, 1998).
Selection effects have been shown empirically to be present for a wide range of adolescent behaviors. Kandel (1978) reported that prior homophily on a number of behaviors and attributes is a determinant of friendship formation. Billy and Udry (1985) and Billy et al. (1988) provided evidence that both white girls and white boys have a tendency to choose samesex best friends whose sexual experiences are similar to their own. Psychological literature suggests that the strength of friends' influence is exaggerated whenever it is estimated by the association between children's characteristics and their friends' characteristics (Berndt et al., 2002). Kandel (1978) pointed out two decades ago that ignoring the selection effect would vastly overestimate the influences of friends. Kandel's analysis suggests that the prominent work by Duncan et al. (1972) assessing the effect of friends on educational aspirations exaggerates the estimates by about $100 \%$.

Evidence for our hypothesis will have implications for the debate of friends versus selection effects. If best friends are, indeed, to some extent, genetically similar, it would suggest a genetic role in friendship selection and formation even though our data can't inform on the mechanisms of the selection and formation.

\section{Friends Data From Add Health}

A common methodological issue in the research on friends' influence is using the same children to report on both their own attitudes and behaviors and their friends' attitudes and behaviors. In a study on school involvement and disruptive behavior, Berndt and Keefe (1995) showed that the estimates of friends' influence are generally higher for measures derived from students' reports on friends than for measures derived from the friends' self-reports. The discrepancy exists because children believe they are more similar to their friends than they actually are (Aboud \& Mendelson, 1996). When children are asked to report their friends' attitudes and behavior, they tend to project their own attitudes and behavior onto their friends. Previous work in sociology comparing measures on perception of behavior with measures on actual behavior has also demonstrated this projection tendency for sexual behavior among boys (Wilcox \& Udry, 1986) and for smoking and drinking behavior among male and female adolescents (Fisher \& Bauman, 1988).

\section{Research Design}

To investigate genetic similarity with respect to a trait such as cognitive ability among friends, an ideal approach is to identify the specific genes associated with the trait. Evidence that the genes of friends were significantly more similar than the genes of nonfriends would suggest a genetic basis for homophily with respect to the trait. In the absence of such measures, we turn to indirect methods that take advantage of the information contained in genetically related individuals. 
As the genetic relatedness between $A$ and $B$ varies,

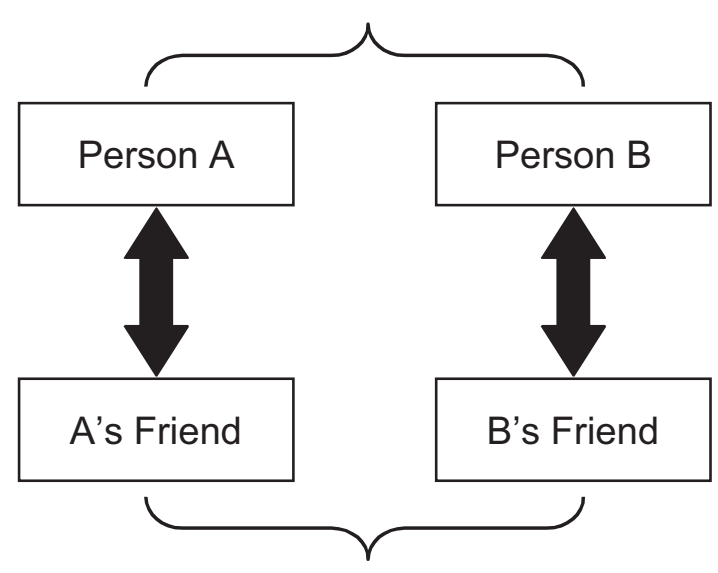

does the similarity between A's and B's friend vary correspondingly?

\section{Figure 1}

Research design for studying the genetic basis for friendship selection.

Figure 1 describes one unit of our analysis. Each unit consists of four individuals: Person A (A), Person $\mathrm{B}(\mathrm{B})$, A's friend $(\mathrm{AF})$, and B's friend (BF). A working sample was contructed for each trait analyzed; a working sample typically contains several hundreds of such units. Previous work suggests that A and AF are likely to be similar with respect to certain personal characteristics ( $\mathrm{B}$ and $\mathrm{BF}$ is equivalent to $\mathrm{A}$ and $\mathrm{AF}$, and will be omitted when appropriate). However, similarity between friends may not be evidence for genetic basis for friendship. For a test of whether best friends share a genetic similarity, advantage was taken of data consisting of four types of units described by Figure 1: (1) units in which $A$ and $B$ form a $M Z$ twin pair, (2) units in which $\mathrm{A}$ and $\mathrm{B}$ form a DZ twin pair, (3) units in which A and B form a same-sex full sibling pair, and (4) units in which A and B are unrelated same-sex pairs randomly selected from the Add Health data. After type (2) units are analyzed alone, types (2) and (3) units will be combined to increase sample sizes; types (2) and (3) units can be combined because DZ twins and full siblings share the same amount of genetic material.

Our hypothesis is primarily interested in the relationship between A and AF. However, a direct estimation of the similarity or correlation between A and $\mathrm{AF}$ does not provide evidence on whether the relationship is genetic or not. For the hypothesis testing, we rely on the research design described in Figure 1. The design can be viewed as a quasi 'experiment' in which we vary the genetic relatedness between A and $\mathrm{B}$, and record any corresponding systematic variations in the similarity between $\mathrm{AF}$ and $\mathrm{BF}$ with respect to some individual characteristics. The crucial feature of the research design is that the two structures ([1] a pair of $M Z$ twins with their best friends, and [2] a pair of DZ twins with their best friends) are the same except that the amount of genetic material shared between MZ twins are twice as much as that between DZ twins. Therefore, if the MZ twins' friends are more similar than DZ twins' friends, genetic factors must be implicated.

It is assumed that (1) the genetic similarity between $\mathrm{A}$ and $\mathrm{AF}$ (if it exists) does not vary by whether A and $\mathrm{B}$ are $\mathrm{MZ}$ or DZ twins, (2) the environments for identical twins are no more similar than the environments for fraternal twins (the usual equal environments assumption for twin analysis), and (3) there is a genetic contribution to the four traits/behaviors (Grade Point Average [GPA], the version Peabody Picture Vocabulary Test [PPVT] designed for Add Health [AHPVT], aggression and depression) examined in this analysis.

Table 1 is constructed to illustrate the reasoning. To fix the idea, two cases are considered: the case in which a genetic similarity is, indeed, shared by A and $\mathrm{AF}$, and the case in which a genetic similarity is not shared. In both cases, regardless of the type of twins used, correlation between $\mathrm{AF}$ and $\mathrm{BF}$ for certain traits and behaviors will be expected because (1) A and B are correlated since they are DZ or MZ twins and share genetic and common environmental factors, and (2) best friends (A and AF) are correlated whether or not genetic factors are involved (first column of the expected empirical results). However, if a genetic similarity is shared among best friends, the correlation between $\mathrm{AF}$ and $\mathrm{BF}$ for $\mathrm{MZ}$ twins will be stronger than that of the DZ twins. The source of this stronger correlation is the greater genetic relatedness between $\mathrm{MZ}$ twins (between $\mathrm{A}$ and $\mathrm{B}$ ) than $\mathrm{DZ}$ twins.

We will deem our hypothesis of a genetic similarity among best friends supported if empirical evidence shows a stronger correlation between $\mathrm{AF}$ and $\mathrm{BF}$ for a greater genetic relatedness between $\mathrm{A}$ and $\mathrm{B}$. Our hypothesis will predict that when $\mathrm{A}$ and $\mathrm{B}$ are a randomly selected pair, AF and BF should not be more similar than randomly paired individuals; when $\mathrm{A}$ and $\mathrm{B}$ are DZ twins, $\mathrm{AF}$ and $\mathrm{BF}$ are substantially more similar than a randomly selected pair, and that when $\mathrm{A}$ and $\mathrm{B}$ are $\mathrm{MZ}$ twins, $\mathrm{AF}$ and $\mathrm{BF}$ are significantly more similar than when $\mathrm{A}$ and $\mathrm{B}$ are $\mathrm{DZ}$ twins. The importance of the role genes play is signified by the extent of the increase in similarity between $\mathrm{AF}$ and $\mathrm{BF}$ corresponding to the increase in genetic similarity between $\mathrm{A}$ and $\mathrm{B}$.

At least two other factors can influence the results of the 'experiment'. First, genetic similarity between friends is likely to be trait-specific. Our objective is not to investigate the role the entire genome plays in friendship formation or whether friends as whole persons are genetically similar. Rather, we investigate whether genetic heritage for a number of personal traits is implicated in friendship formation. Of the 
Table 1

Hypothesis Testing Using Our Research Design

\begin{tabular}{lccc}
\hline Genetic similarity among best friends & Type of twins & Expected empirical results \\
\hline Shared & & $\begin{array}{c}\text { Correlation between AF \& BF } \\
\text { stronger for MZ than DZ? }\end{array}$ & Yes correlated? \\
\hline Not shared & MZ twins & Yes & Yes (our hypothesis supported) \\
& DZ twins & Yes & No (our hypothesis not supported) \\
\hline
\end{tabular}

four traits investigated, we predict a markedly stronger genetic similarity among friends with respect to academic performance than with respect to, say, depression. Individuals may want their friends to be like themselves on some characteristics, but not others. Individuals are likely to seek friends who are at a similar level of academic performance. On the other hand, individuals may or may not want to seek friends with a similar level of depression.

Second, criteria for selecting same-sex friends may be different from criteria for selecting different-sex friends. A same-sex friendship is when A and AF or B and $\mathrm{BF}$ are of the same sex. The level of academic performance should be an important factor for samesex friends as well as different-sex friends, but we expect stronger results from the same-sex friends than different-sex friends.

To avoid this potential confounding effect, an adjustment was made at two levels. At the level of the unit of analysis as described in Figure 1, we made sure that the full sibling pair in each unit of analysis was of the same sex. Then at the analysis level, all outcomes were analyzed twice: once using same-sex friends and once using different-sex friends (A and AF are of the same sex).

\section{Data and Analytical Methods \\ Sample and Measures}

The data for the analysis come from the sibling sample within the Add Health, which is a school-based study that focuses on the health-related behaviors of students in grades 7 through 12 in 1994 in the United States. Add Health has deliberately incorporated the behavior-genetic designs as components in an otherwise traditional survey. The sibling sample is composed of six groups: MZ twins, DZ twins, full biological siblings, half biological siblings, cousins, and biologically unrelated adolescents living in the same household. The result is an unprecedented genetic sample for a national study of this magnitude.

In Waves I (1994) and II (1995), the classification of the twins into $\mathrm{MZ}$ pairs and $\mathrm{DZ}$ pairs was based primarily on self-reports of confusability of appearance. At Wave III in 2002, DNA samples were collected from a subset of the Add Health sample. The subset consisted of $2574 \mathrm{MZ}$ twins, DZ twins, and full biological siblings. For these individuals, genomic DNA was isolated from buccal cells using a modification of published methods. The zygosity of the twins was then redetermined at the DNA level through a comparison of their match on 12 unlinked STR (http://www.cpc.unc.edu/projects/addhealth/).

In the analysis, $M Z$ twin pairs, DZ twin pairs, and full biological sibling pairs were drawn from 'in-home' Add Health data. Different-sex DZ twin pairs and different-sex full sibling pairs were removed from the analysis (when A and B are of different sex, see Figure 1) because the nature of the relationship between two female friends (A and AF) may be considerably different to the relationship between two male friends (B and $\mathrm{BF}$ ).

Respondents in Add Health were asked to nominate same-sex and different-sex friends starting with the closest friend, including girlfriends and boyfriends. To construct the unit of analysis described in Figure 1, one same-sex and one opposite-sex friend were selected from these nominations for each adolescent in the genetic pair samples. The grades from which GPA were calculated were gathered in both the school questionnaire and the in-home interview. On the other hand, AHPVT, aggressive behavior, and depression were only available in the home interview. Since fewer friends have data on these measures, our analyses of these measures contain fewer cases than the analysis of GPA. The actual samples sizes used will be described along with the description of our analysis results.

Our sibling sample consists of adolescents aged between 13 and 18 years in $1994(M=15.7, S D=1.79)$. About $50 \%$ of the sibling sample was male. Of the adolescents, about $60 \%$ were white Americans, $12.8 \%$ nonwhite Hispanics, and $14.8 \%$ African Americans. These descriptive statistics vary somewhat by analysis samples that were used to analyze the four traits. Four traits were examined: GPA $(M=2.70, S D=0.76)$, AHPVT $(M=102.1, S D=13.5)$, aggressiveness $(M=.21, S D=0.403)$, and depression $(M=1.58$, $S D=0.38$ )

GPA is the friend's self-reported mean letter grade for English, mathematics, science, and history. AHPVT with 78 items is an abridged version of the Peabody Picture Vocabulary Test (PPVT) especially designed for Add Health. The PPVT measures an 
individual's receptive (hearing) vocabulary for Standard American English and provides, at the same time, an estimate of verbal ability or scholastic aptitude (Dunn \& Dunn, 1981). The test was given to adolescents present at the in-home Wave I survey. PPVT has been used widely as a measure of academic performance in social sciences (e.g., Duncan \& Brooks-Gunn, 1997; Moore \& Snyder, 1991).

Aggression was measured by the average of the responses to four questions. Respondents reported how often during the past year they had (1) gotten into a serious fight, (2) hurt someone badly, (3) used (or threatened to use) a weapon, and (4) taken part in a gang fight. The response categories ranged from 0 (never) to 3 (five or more times).

The depression variable was intended to measure psychological health based on the adolescents' responses to questions from the CES-D Scale (Radloff, 1977), the Beck Inventory (Beck, 1978), and several interview questions pertaining to the respondent's general health (see Appendix A). The depression index, which represents the mean item score across 23 items that measure different aspects of depressive symptoms, has a reliability of .879 . Original responses were ordinal in nature, ranging from 1 (never) to 4 (all the time). Thus, a higher depression index score indicates more depressive symptoms.

\section{Statistical Models}

Correlation coefficients were used to measure the homophily between $\mathrm{AF}$ and $\mathrm{BF}$ with respect to a personal characteristic. For exploratory purposes, this can be accomplished by Pearson's correlation procedure. But for calculating correlation coefficients while controlling for age, regression methods were used. The structural equation model (Neale \& Cardon, 1992) has been the standard method for analyzing twin and sibling data. More recently, Guo and Wang (2002) showed that the mixed model or the multilevel model (which has long been established in statistical literature [Bryk \& Raudenbush, 1992; Searle, 1971; Searle et al., 1992]) and included as a standard procedure in many major statistical packages including SAS and SPSS) can be used for the analysis of biometrical data. Guo and Wang (2002) demonstrated that the mixed model generally yielded results equivalent to those from the SEM/Mx. Skrondal and Rabe-Hesketh (2004) showed the equivalence between the structural equation models and the multilevel models.

A genetically informative sibling sample is essentially a sample of correlated observations with the correlation created by shared environmental and genetic influences among siblings. The following mixed model estimates correlation coefficients while taking into account the age of the siblings:

$$
Y_{i j(t)}=\beta_{0}+\beta_{1} a g e_{i j}+u_{j(t)}+e_{i j(t)}
$$

where $Y_{i j(t)}$ is the trait for adolescent $i$ in pair $j$ for pair type $t$ (MZ twins, DZ twins, DZ twins and full siblings), $\beta_{0}$ is the intercept, $\beta_{1}$ is the coefficient for age, $u_{j(t)}$ is the pair-specific random effect for pair type $t$, and $e_{i j}$ is the individual-specific random effect or the ordinary least squares-like error term. The standard assumptions are that $u_{j}$ and $e_{i j}$ are mutually independent $N\left(0, \sigma_{u}^{2}\right)$ and $N\left(0, \sigma_{e}^{2}\right)$ random variables. The within-pair correlation between $\mathrm{AF}$ and $\mathrm{BF}$, adjusted for age, for sibling type $t$ can be obtained from an $\rho_{t}=\sigma_{u t}^{2} /\left(\sigma_{u t}^{2}+\sigma_{e t}^{2}\right)$. Our hypothesis is that $\rho_{M Z}$ is significantly larger than $\rho_{D Z}$ and than $\rho_{D Z+\text { fullsib }}$.

A formal comparison can be carried out via statistical hypothesis testing using the null hypothesis $H_{0}: \rho_{M Z} \leq \rho_{D Z}$ or $H_{0}: \rho_{M Z} \leq \rho_{D Z+\text { fullsib }}$. We carried out this test using the bootstrapping method (Efron \& Tibshirani, 1993), which has long become a standard tool in the statistical literature for a wide range of statistical problems. The computationally intensive bootstrapping method resamples the data by pair (without breaking up the pairs) with replacement for 2000 times, each time reestimating the mixed model and recalculating $\rho_{M Z}-\rho_{D Z}$. The 2000 estimates of $\rho_{M Z}-\rho_{D Z}$ are then ranked. The $95 \%$ confidence interval can be constructed by the 2.5 th and 97.5 th percentiles of the $\rho_{M Z}-\rho_{D Z}$ estimates.

\section{Results}

Table 2 provides estimated correlation coefficients between AF and BF for GPA, AHPVT, aggression, and depression. The correlation coefficients are estimated separately for friends of MZ twins, friends of DZ twins, and friends of DZ twins and full siblings as well as friends of randomly paired individuals from the sibling sample of the Add Health. The correlation coefficients are estimated separately for friendships between the same genders and friendships between different genders. The number of sibling pairs used for the calculation is given in the parenthesis. The $95 \%$ bootstrapping confidence intervals for the difference in correlation coefficient between the MZ twins and DZ twins as well as between the $\mathrm{MZ}$ twins and the combined sample of DZ twins and full siblings are located towards the end of each row.

When a friendship is between same-gender siblings, the correlation for GPA between MZ twins' friends (.55) is larger than that between DZ twins' friends (.24) and that between DZ twins' and full siblings' friends (.25). The bootstrapping resampling analysis shows a $95 \%$ confidence interval of 0.15 , 0.55 for the MZ/DZ difference and an interval of $0.16,0.46$ for the $\mathrm{MZ} /(\mathrm{DZ}$ and full sibling) difference, pointing to evidence for a role of genes for GPA in the formation of friendship. The analysis of different-sex pairs has yielded a different pattern of results with a $95 \%$ confidence interval of $-0.08,0.40$ for the MZ/DZ difference.

We consider AHPVT another measure of academic performance in the present context and expect results from AHPVT to be similar to those on GPA. For the same-gender friends, the MZ twin correlation (.64) is substantially larger than that for DZ twins (.46), 
Table 2

Estimated Correlation Coefficients

\begin{tabular}{|c|c|c|c|c|c|c|c|}
\hline \multirow[t]{2}{*}{ Traits/behaviors } & \multirow[t]{2}{*}{ Pair type } & \multicolumn{4}{|c|}{ Correlation coefficient ( $N$ of Pairs) } & \multicolumn{2}{|c|}{$95 \%$ bootstrapping $\mathrm{Cl}$} \\
\hline & & MZ twins & DZ twins & $D Z+$ full sibs & Random pairs & (MZ-DZ) & (MZ-[DZ + full sib]) \\
\hline \multirow[t]{2}{*}{ GPA } & same sex & $.55(184)$ & $.24(147)$ & $.25(606)$ & $.025(500)$ & $0.15-0.55$ & $0.16-0.46$ \\
\hline & different sex & $.40(123)$ & $.33(101)$ & $.21(444)$ & $.029(500)$ & $-0.08-0.40$ & $0.02-0.40$ \\
\hline \multirow[t]{2}{*}{ PPVT } & same sex & $.64(100)$ & $.46(67)$ & $.44(349)$ & $.026(500)$ & $-0.05-0.53$ & $0.001-0.40$ \\
\hline & different sex & $.49(37)$ & $.62(33)$ & $.37(224)$ & $.030(500)$ & $-0.36-0.51$ & $-0.10-0.58$ \\
\hline \multirow[t]{2}{*}{ Aggression } & same sex & $.73(106)$ & $.14(78)$ & $.18(361)$ & $.034(500)$ & $0.22-0.82$ & $0.25-0.75$ \\
\hline & different sex & $.16(39)$ & $.24(38)$ & $.20(235)$ & $.046(500)$ & $-0.41-0.41$ & $-0.30-0.37$ \\
\hline \multirow[t]{2}{*}{ Depression } & same sex & $.49(106)$ & $.29(78)$ & $.26(361)$ & $.025(500)$ & $-0.22-0.54$ & $-0.12-0.46$ \\
\hline & different sex & $.33(37)$ & $.43(38)$ & $.15(237)$ & $.027(500)$ & $-0.61-0.27$ & $-0.19-0.46$ \\
\hline
\end{tabular}

Note: Estimated correlation coefficients (number of pairs) between A's friend and B's friend for four individual characteristics by sibling type (MZ, DZ, or DZ and full siblings) and by whether the friendship is between the same gender or different gender (see Figure 1); also included is the $95 \%$ bootstrapping confidence intervals for the gap in correlation coefficient between $\mathrm{MZ}$ and $\mathrm{DZ}$ and between $\mathrm{MZ}$ and $\mathrm{DZ}$ plus full siblings.

giving a difference of .18 and a $95 \%$ confidence interval of $-0.05,0.53$. The same-sex difference between $\mathrm{MZ}$ twins and the combined sample of DZ twins and full siblings is similar (.20) with a $95 \%$ confidence interval of $0.001,0.40$. The results for the differentgender friends again show a different pattern from those for the same-sex data.

The correlation for random pairs ranging from .025 to .030 is negligible for both same-gender and different-gender friends. The random pairs, paired randomly by individuals within the Add Health sibling sample, are expected to be uncorrelated with respect to any of the four characteristics under consideration in this analysis. The random-pair analysis is intended to provide a set of baseline results against which the results from sibling data can be compared. The random-pair result is the average of 100 simulated samples of 500 pairs each.

Like GPA and AHPVT, we had expected to find empirical support for our hypothesis for aggression particularly for the same-gender pairs. The empirical support for our hypothesis for aggression is evident. For the same-gender friends, the correlation for DZ twins (.14) and for DZ twins and full siblings (.18) are only a fraction of that for $\mathrm{MZ}$ twins (.73). The bootstrapping procedures yield two corresponding $95 \%$ confidence intervals of $0.22,0.82$ and $0.25,0.75$. In contrast, for the different-gender friends, the three correlations are $.16, .24$, and .20 , respectively, with two corresponding confidence intervals of $-0.41,0.41$ and $-0.30,0.37$.

Although the point estimates for depression from the same-sex friends do indicate a stronger correlation for MZ twins (.46) than for DZ twins (.29) and for DZ twins and full siblings (.26), the $95 \%$ confidence intervals of $-0.22,0.54$ and $-0.12,0.46$ fail to confirm that the two differences are statistically significant. The analysis of the different-sex friends does not show any statistically significant difference between $\mathrm{MZ}$ and DZ twins or between MZ twins and the combined sample of $\mathrm{DZ}$ twins and full siblings.
We have estimated the correlation coefficients between the siblings with respect to the four traits in addition to the correlation between the siblings' friends. The former is generally stronger than the latter. For example, the correlation between the $\mathrm{MZ}$ twins for GPA is .68 as compared with the correlation of .55 (Table 2) between the friends of the MZ twins. Similarly, the two estimated correlation coefficients for AHPVT are .81 for the MZ twins and .64 (Table 2) for the friends of the MZ twins, respectively.

\section{$\overline{\text { Discussion }}$}

Our analysis has produced evidence that the resemblance between $\mathrm{AF}$ and $\mathrm{BF}$ is stronger when $\mathrm{A}$ and $\mathrm{B}$ are $\mathrm{MZ}$ twins than when $\mathrm{A}$ and $\mathrm{B}$ are $\mathrm{DZ}$ twins or when $A$ and $B$ are DZ twins or full siblings. As expected, the evidence only comes from the analysis of same-sex friends. Of the four traits or behaviors under consideration, GPA and aggression have yielded statistically significant results by the bootstrapping procedure, that is, the difference in correlation between $M Z$ and DZ twins is significant. So is the difference between $M Z$ twins and the combined sample of DZ twins and full siblings. The results for AHPVT are only significant for $\mathrm{MZ}$ twins versus the combined sample of $M Z$ twins and full siblings. The difference between MZ and DZ twins for AHPVT is close to but not quite significant. For depression, the analysis of same-sex friend pairs did not yield a statistically significantly stronger correlation for $\mathrm{MZ}$ twins.

We consider these findings evidence for a genetic similarity shared by best friends among adolescents in the United States. The MZ twins, DZ twins, and full siblings have isolated genetic from environmental correlation among best friends and provide an instrument through which the genetic similarity between A and AF can be identified. Our research design assumes that the structure for $\mathrm{MZ}$ twins is the same as that for $\mathrm{DZ}$ twins. The design attributes changes in the correlation between $\mathrm{AF}$ and $\mathrm{BF}$ to (1) the changes in the genetic 
relatedness between the twins/siblings and (2) the existence of a genetic similarity between $\mathrm{A}$ and $\mathrm{AF}$. If $\mathrm{AF}$ is completely unrelated to A genetically, the increased similarity due to increased genetic relatedness alone between $\mathrm{A}$ and $\mathrm{B}$ will not be reflected in the increased similarity between $\mathrm{AF}$ and $\mathrm{BF}$.

These data must be interpreted with caution. Even if friends are, indeed to some extent, genetically alike, friends do not receive the same genes the way biologically related siblings receive the same genes from their parents. A substantially greater variety of patterns must exist with respect to genetic relatedness among best friends than among biological relatives. For example, friendship decisions are probably based on phenotype rather than genotype recognition, suggesting a role by genetic heterogeneity, defined as distinct gene sequences at the same locus (allelic heterogeneity) or different loci (nonallelic heterogeneity) responsible for indistinguishable phenotypes. Not all individuals seek friends who are similar to themselves in certain traits and behaviors. Among those who do seek friends similar to themselves, not all individuals look for the same set of traits and behaviors in their friends. Our results are an average of all extant patterns observed in the sample.

The suggested genetic basis for homophily among friends is trait-specific. The existence of a genetic basis for measures like GPA and cognitive test scores does not necessarily imply a genetic basis for another trait. Depression could be one of those traits. We have reasoned that the larger the gap between the correlation for the MZ twins' friends and the correlation for DZ twins' friends, the larger the role genes might have played in friendship formation. But we do not know the exact size of the genetic role because no heritability can be derived from the correlation estimates for the trait in question.

More MZ twins (15.7\%) than DZ twins (7\%) nominate the other twin as a best friend. However, this does not necessarily lead to an overestimation of the genetic component. Indeed, if there is a genetic contribution to friendship formation, we would expect the number to be larger for MZ twins than DZ twins.

Our empirical findings are in support of Rushton's (1989) hypothesis of genetic similarity at least in the case of best friends among adolescents. Recognizing the genetic contribution for homophily in adolescent friendships has also important implications for understanding the nature of friend or peer influences. Social scientists have long suspected an essential role of peer influences in shaping the behavior of adolescents. Abundant evidence has been found linking individuals' behavior with their friends' behavior. The traditional approach tends to attribute all of this linkage to friends' influence. While recognizing that part of the linkage may well be friends' influence, more recent work argues that part of the linkage may be due to selection and that ignoring selection would exaggerate friends and peer influences. Our analysis has not only provided evidence for the selection argument, but has also shown that part of the selection may be genetically based.

\section{Acknowledgments}

Special thanks go to Laura Burns and Seulki Choi for their extensive contribution to the project. The study was supported in part by the W. T. Grant Foundation, the American Sociological Association's Fund for the Advancement of the Discipline Award, R03 HD042490-02 from the National Institute of Child Health and Human Development, and 5-37124 from the National Science Foundation.

\section{$\overline{\text { References }}$}

Aboud, F. E., \& Mendelson, M. J. (1996). Determinants of friendship selection and quality: Developmental perspectives. In W. M. Bukowski, A. F. Newcomb, \& W. W. Hartup (Eds.), The company they keep: Friendship in childhood and adolescence (pp. 87-112). New York: Cambridge University Press.

Baker, L. A., \& Daniels, D. (1990). Nonshared environmental influences and personality differences in adult twins. Journal of Personality and Social Psychology, 58, 103-110.

Bandura, A. (1977). Social learning theory. Englewood Cliffs, NJ: Prentice Hall.

Bauman, K., \& Ennett, S. (1996). On the importance of peer influence for adolescent drug use: Commonly neglected considerations. Addiction, 91, 185-198.

Bearman, P., \& Bruckner, H. (2000). Peer effects on adolescent girls' sexual debut and pregnancy [Research monograph]. Washington, DC: National Campaign to Prevent Teen Pregnancy.

Beck, A. T. (1978). Depression Inventory. Philadelphia, PA: Center for Cognitive Therapy.

Berelson, B., Lazarsfeld, P. F., \& McPhee, W. (1954). Voting. Chicago: University of Chicago Press.

Berkowitz, W. R. (1969). Perceived height, personality, and friendship choice. Psychological Reports, 24, 373-374.

Berndt, T. J. (1999). Friends' influence on children's adjustment to school. In W. A. Collins \& B. Laursen (Eds.), The Minnesota symposia on child psychology. Vol. 30: Relationships as developmental contexts (pp. 85-107). Mahwah, NJ: Erlbaum.

Berndt, T. J., \& Keefe, K. (1995). Friends' influence on adolescents' adjustment to school. Child Development, 66, 1312-1329.

Berndt, T. J., Murphy, J., \& Lonna, M. (2002). Influence of friends and friendships: Myths, truths, and research recommendations. In R. Kail (Eds.), Advances in child development and behavior (pp. 275-310). New York: Elsevier Science.

Berscheid, E., \& Walster, E. (1978). Interpersonal attraction (2nd ed.). New York: Random House. 
Billy, J. O. G., Landale, N. S., Grady, W. B., \& Zimmerle, D. M. (1988). Effects of sexual activity on adolescent social and psychological development. Social Psychology Quarterly, 51, 190-212.

Billy, J. O. G., \& Udry, J. R. (1985). Patterns of adolescent friendship and effects on sexual behavior. Social Psychology Quarterly, 48, 27-41.

Bronfenbrenner, U. (1967). Response to pressure from peers versus adults among Soviets and American school children. International Journal of Psychology, 2, 199-207.

Bronfenbrenner, U. (1970). Reaction to social pressure from adults versus peers among Soviet day school and boarding school pupils in the perspective of an American sample. Journal of Personality and Social Psychology, 15, 179-189.

Bryk, A. S., \& Raudenbush, S. W. (1992). Hierarchical linear models: Applications and data analysis methods. Newbury Park, CA: Sage.

Daniels, D., \& Plomin, R. (1985). Differential experience of siblings in the same family. Developmental Psychology, 21, 747-60.

Dishion, T. J., McCord, J., \& Poulin, F. (1999). When interventions harm: Peer groups and problem behavior. American Psychologist, 54, 755-764.

Dishion, T. J., Poulin, F., \& Burraston, B. (2001). Peer group dynamics associated with iatrogenic effects in group interventions with high-risk young adolescents. In D. W. Nangle \& C. A. Erdley (Eds.), The role of friendship in psychological adjustment: New directions for child and adolescent development (No. 91; pp. 79-92). San Francisco: Jossey-Bass.

Duncan, G., \& Brooks-Gunn, J. (1997). Income effects across the life span: Integration and interpretation. In G. J. Duncan \& J. Brooks-Gunn (Eds.), Consequences of growing up poor (pp. 596-610). New York: Russell Sage Foundation.

Duncan, O. D., Featherman, D. L., \& Duncan, B. (1972). Socioeconomic background and achievement. New York: Seminar Press.

Dunn, L. M., \& Dunn, L. M. (1981). PPVT-R manual. Circle Pines, MN: American Guidance Service.

Efron, B., \& Tibshirani, R. J. (1993). An introduction to the bootstrap. Chapman \& Hall, New York.

Fisher, L. A., \& Bauman, K. (1988). Influences and selection in the friend-adolescent relationship: Findings from studies of adolescent smoking and drinking. Journal of Applied Social Psychology, 18, 289-314.

Guo, G., \& Wang, J. (2002). The mixed or multilevel model for behavior genetic analysis. Behavior Genetics, 32, $37-49$.

Harris, J. R. (1995). Where is the child's environment? A group socialization theory of development. Psychological Review, 102, 458-489.

Harris, K. M., Florey, F., Tabor, J., Bearman, P. S., Jones, J., \& Udry, J. R. (2003). The National Longitudinal Study of Adolescent Health: Research design. Retrieved May,
2005, from http://www.cpc.unc.edu/projects/addhealth/ design

Hartup, W. W. (1983). Peer relations. In P. H. Mussen (Series Ed.) \& E. M. Hetherington (Vol. Ed.), Handbook of child psychology. Vol. 4: Socialization, personality, and social development (4th ed.; pp. 103-196). New York: Wiley.

Hamilton, W. D. (1964). The genetical evolution of social behavior: I and II. Journal of Theoretical Biology, 7, $1-52$.

Iervolino, A. C., Pike, A., Manke, B., Reiss, D., Hetherington, E. M., \& Plomin, R. (2002). Genetic and environmental influences in adolescent peer socialization: Evidence from two genetically sensitive designs. Child Development, 73, 162-174.

Kandel, D. B. (1978). Homophily, selection, and socialization in adolescent friendships. American Journal of Sociology, 84, 427-436.

Lazarsfeld, P. F., \& Merton, R. K. (1954). Friendship as a social process. In M. Berger, T. Abel, \& C. H. Page (Eds.), Freedom and control in modern society (pp. 18-66). Princeton, NJ: Van Nostrand.

Manke, B., McGuire, S., Reiss, D., Hetherington, E. M., \& Plomin, R. (1995). Genetic contribution to adolescents' extrafamilial social interactions: Teachers, best friends, and peers. Social Development, 4, 238-256.

Matsueda, R. (1982). Testing control theory and differential association: A causal modeling approach. American Sociological Review, 47, 489-504.

Matsueda, R. L., \& Heimer, K. (1987). Race, family-structure, and delinquency: A test of differential association and social-control theories. American Sociological Review, 52, 826-840.

Moffitt, R. A. (1998). Policy interventions, low-level equilibria, and social interactions. Unpublished manuscript.

Moore, K., \& Snyder, N. (1991). Cognitive attainment among firstborn children of adolescent mothers. American Sociological Review, 56, 612-624.

Neale, M. C., \& Cardon, L. R. (1992). Methodology for genetic studies of twins and families. Dordrecht, the Netherlands: Kluwer Academic.

Piaget, J. (1932/1965). The moral judgment of the child. New York: Free Press.

Plomin, R., DeFries, J. C., Craig, I. W., \& McGuffin, P. (2003). Behavior genetics in the postgenomic era. Washington, DC: American Psychological Association.

Plomin, R., DeFries, J. C., McClearn, G. E., \& McGuffin, P. (2001). Behavior genetics (4th ed.). New York: Worth.

Radloff, L. S. (1977). The CES-D scale: A self-report depression scale for research in the general public. Applied Psychology Measurement, 1, 385-401.

Rodgers, J. L., Rowe, D. C., \& Buster, M. (1999). Nature, nurture and first sexual intercourse in the USA: Fitting behavioral genetic models to NLSY kinship data. Journal of Biosocial Science, 31, 29-41. 
Rowe, D. C., \& Osgood, D. W. (1984). Heredity and sociological theories of delinquency: A reconsideration. American Sociological Review, 49, 526-540.

Rushton, J. P. (1989). Genetic similarity, human altruism, and group selection. Behavioral and Brain Sciences, 12, 503-559.

Rushton, J. P., \& Bons, T. A. (2005). Mate choice and friendship in twins: Evidence for genetic similarity. Psychological Science, 16, 555-559.

Scarr, S., \& McCartney, K. (1983). How people make their own environments: A theory of genotype greater than environment effects. Child Development, 54, 424-435.
Searle, S. R. (1971). Linear models. New York: Wiley.

Searle, S. R., Casella, G., \& McCulloch, C. (1992). Variance components. New York: Wiley.

Skrondal, A., \& Rabe-Hesketh, S. (2004). Generalized latent variable modeling: Multilevel, longitudinal, and structural equation models. London: Chapman \& Hall/CRC.

Wilcox, S., \& Udry, J. R. (1986). Autism and accuracy in adolescent perceptions of friends' sexual attitudes and behavior. Journal of Applied Social Psychology, 16, $361-374$.

\section{$\overline{\text { Appendix }}$ \\ Depression Index (23 items; Cronbach's Alpha = .879)}

Please tell me how often you have had each of the following conditions in the past 12 months. Answers range from 1 (never) to 4 (every day).

1. Feeling very tired, for no reason.

2. Waking up feeling tired.

3. Poor appetite.

4. Moodiness.

5. Frequent crying.

6. Fearfulness.

7. In the last month, how often did a health or emotional problem cause you to miss a day of school?

8. In the last month, how often did a health or emotional problem cause you to miss a social or recreational activity?

How often was each of the following things true during the past week? Answers range from 1 (never or rarely) to 4 (most of the time or all of the time).

1. You were bothered by things that usually don't bother you.

2. You didn't feel like eating, your appetite was poor.

3. You felt that you could not shake off the blues, even with help from your family and your friends.

4. You had trouble keeping your mind on what you were doing.

5. You felt depressed.

6. You felt that you were too tired to do things.

7. You thought your life had been a failure.

8. You felt fearful.

9. You talked less than usual.

10. You felt lonely.

11. People were unfriendly to you.

12. You felt sad.

13. You felt that people disliked you.

14. It was hard to get started doing things.

15. You felt life was not worth living. 